Article

\title{
Reframing HRI Design Opportunities for Social Robots: Lessons Learnt from a Service Robotics Case Study Approach Using UX for HRI
}

\author{
Sara Khan * and Claudio Germak \\ Department of Architecture and Design, Politecnico di Torino, Corso Duca degli Abruzzi 24, \\ 10129 Turin, Italy; claudio.germak@polito.it \\ * Correspondence: sara.khan@polito.it
}

Received: 6 September 2018; Accepted: 1 October 2018 ; Published: 10 October 2018

check for updates

\begin{abstract}
Over the last few decades, semi-autonomous machine's technology started to promote awareness towards the importance of human-robot interaction (HRI) for improving daily activities. More affordable social robots are being commercially released and in order to implement viable applications of HRI, a combination human-computer interaction and user experience methodologies could play a pivotal role in assessing new scenarios and evaluating new investigations. However, literature shows that it is still challenging to reach an optimal user experience with robotic companions. The aim of the study was to determine the chance to enhance the user experience with a semi-autonomous social robot, using user experience and human-computer interaction methodologies. In this study, a social robotic companion has been developed and prototyped in order to be adopted in a specific public environment such as a company workspace. The challenges emerged from this peculiar environment triggered the need for a more productive and comfortable office for the employees, and, at the same time, the usability, acceptance and likeability of the robotic companion have been evaluated. The results emphasize that, since HRI is highly interdisciplinary, the benefits of combining approaches from other fields could positively benefit from a meaningful social interaction with the users.
\end{abstract}

Keywords: human-robot interaction (HRI); user experience (UX); human-computer interaction (HCI); user centred design; HCI for HRI; UX methods; social robots

\section{Introduction}

In the last two decades, a growing body of literature started to recognize the importance of making workspaces more comfortable for workers and increasing efficiency [1,2]. In order to tackle this issue, the field of human-computer interaction (HCI), user experience (UX) and human-robot interaction (HRI) started to explore different scenarios of application [3,4]. The various scenarios included many public environments such as hospitals, airports, and any kind of background that can be perceived as overwhelming due to the high volume of screens, background noise, and people within a relatively small space [5]. Common and public spaces are usually considered a breeding ground for confusion, stress and anxiety, therefore working in such an environment could be detrimental to the employees' well being and efficiency $[6,7]$.

In this investigation, it will be highlighted how the application of HCI and UX methodology in the HRI field will bring mutual benefits to these disciplines, and which results are possible to achieve or could be implemented. Specifically, a case study regarding the enhancement of the user experience inside a company workspace will be discussed. In the pages that follow, it will be argued that a service robotics application can be tested in order to verify and evaluate a positive UX with a social robot. 
In order to enhance the user experience inside a company workspace, a social robot experience has been tested in order to verify and evaluate a positive UX with a robot courier. In this peculiar setting, the employees' efficiency and well being can benefit from a social robot that can be "uniquely positioned to provide assistance in ways that other technologies cannot. They may elicit social and emotional responses" [8]. However, according to Tonkin, bringing into this environment a new technology for use, such as a social robot, should be handled cautiously in an attempt to avoid a scenario where people could feel negatively impacted [3]. In addition, such a technology could become an interesting ground to test new ways to improve employees' productivity and comfort, and also provide insight into the challenges of HRI and HCI $[9,10]$. With the aim of pursuing these goals, the investigation targeted an enhanced workspace experience supported by the adoption of a robot courier. This social robot was meant to perform daily tasks in a workspace, such as welcoming and providing assistance to visitors in a building complex that is part of a telecommunication company.

Although this study is aimed at achieving and implementing a UX applied inside an office workspace, it is important to consider that a positive experience could be beneficial for other public contexts such as airports, hospitals, train stations or in any environment where a social robot could contribute to deepening research in the field of the contribution from UX to HRI and the array of commercial applications [11].

In this research field, some investigations have already been performed [12,13], showing the importance of creating meaningful UX with social robots [14]. However, evidence suggests that, before designing meaningful UX, it is vital to depict the many aspects of the service design methodology [3]. Taking into account this approach, it can be helpful to understand how to design the UX of social robots and tackle issues concerning the service design's methods that can effectively contribute a positive experience in HRI $[15,16]$. A better experience with social robots is not just helpful to investigate unaddressed challenges in HRI but can be meaningful in increasing the number of robots in public environments $[17,18]$. The increased number of robots in society means that there are possible robotic applications outside of the academic investigation, attracting industry for commercial uses. Exploring possible applications in a specific environment, such as a company's workspace, can significantly contribute to advancing HRI research [17,19].

\section{Background and Related Works}

In this section, the correlations between the HRI studies and the possible benefits derived by the adoption of UX and HCI methods will be presented. In order to better understand these correlations, it is important to take into account a broader view of the research fields involved and the contexts of usage where the robots can be employed. Different contexts can lead to different expectations from the users, and, in order to support a positive user experience, it can be vital for the expectations of the user to match the abilities of the robot.

\subsection{The Added Value of UX of HCI towards HRI for Social Robotics (SR)}

As an essential part of the ongoing interaction between humans and robots, recently different emotional aspects have been investigated in the HCI studies in the HRI field. According to Alenljung [12], some emotional and interactive aspects related to the UX with a social robot, such as engagement, safety, acceptance, cooperation, and likeability, have been widely investigated in HRI but still are poorly connected with UX studies. In this paper, it is argued that UX design can be supportive in pointing out the relevance of evaluating socially interactive robots and user experience design that can be helpful in giving new tools to unfold several issues related to HRI. In addition, it can be useful for practitioners, such as robot developers, to adopt existing techniques from HCI and UX and use them after appropriately shaping them for the context of the HRI [12]. According to Dautenhahn [20], HRI is a "relatively new and growing research field that is concerned with the ways humans might work, play and interact with different kind of robots". There's a wide range of disciplines that are giving a significant contribution to HRI showing diverse perspectives on the research area [20]. An open 
debate started when Dautenhahn [20] shed light on the given benefits of taking into account HRI research from a broader view that "challenge and enhance existing frameworks and embark on new frontiers in HRI" $[12,20]$. Therefore, in this investigation, the emphasis is on the inspiration from HCI and UX studies, explicitly for designing and evaluating various aspects of HRI [21]. As proposed by Alben, to design a meaningful user experience implies undertaking and developing a product as a whole $[15,20]$. For this reason, the investigation proposed in this paper puts forward a practical approach to first identify the two main issues in the field of HRI: (1) how to create a positive user experience in a systematic way with a the robot courier, and (2) how to underline useful applications for social robots at large, giving future guidelines from the lessons learnt from this application. The analysis of the robot courier's case study is not only intended to give evidence of possible commercial applications for a specific environment, such as a company workspace, but also to highlight a wider range of viable applications in HRI that could benefit from a positive user experience methodological application.

According to Ahmad [22], human-robot interaction (HRI) and Social Robotics (SR) are sub-branches of HCI that revolve around designing, implementing and evaluating robotic systems in both controlled environments and real world social settings. The pursuit towards the implementation and development of robot interfaces and social robots in general has also been emphasised in HRI literature [23-25]. In this paper, we will analyse a social robot case study, putting an accent on how human-robot interaction (HRI) and Social Robotics (SR) can be intended as sub-branches of HCI that revolve around designing, implementing and evaluating robotic systems in both controlled environments and real world social settings [22]. The need for more research on HCI, and a positive user experience design and prototyping for social robots, or more precisely socially interactive robots, is strongly linked with the aim of enhancing the practice of robot developers. As stated by Alenjung [12], this practice lacks a better UX analysis, and, with the exception of the investigations carried by Bartneck [26] and Hu (2004), and Syrdal et al. [27] (2009), this aim is missing in HRI [27]. This paper applies a practical methodology to firstly establish doable, and possibly commercial, applications for a social robot in a given environment focusing on users' needs and then comprehensively and systematically designing the user experience for the application and environment.

\subsection{Service Design for Human-Robot Interaction}

Prior to explaining the motivation behind the reason we used User Experience methods and guidelines in this investigation, we should define how user experience can be intended in the field of HRI. According to Tonkin and Hartson, UX guidelines can be intended as an expression of "the totality of the effect or effects felt by a user as a result of interaction with, and the usage context of, a system, device, or product, including the influence of usability, usefulness, and emotional impact during interaction and savouring memory after interaction" [13]. UX is highly related to users' subjective feelings, hence they need to be analysed, taking into account a broader perspective. This new perspective can be highly relevant for a more comprehensive approach in HRI as stated by Lindblom and Andreasson [15]. Understanding the user and the usage context, and designing the interaction with these in mind, it may be possible to positively influence the UX [15]. The relevance of a specific scenario taken into account in UX is referred to by Hassenzahl and Tractinsky [28] and, therefore, the context can play a key role in HRI research as well $[12,29,30]$. Additionally, the scenario in which a social robot could operate has also been identified as of critical importance $[3,31]$ since a positive experiences could be identified as critical to the overall adoption of service robotics in social environments [32]. The inclusion of UX is important in HRI, since a negative user experience may lead future users to accept a social robot [33].

\subsection{Social Robots' Setting Applications: Public Environment}

The need for more efficient office spaces has led to significant changes in their design over the last decade. A huge body of literature is growing in favour of a better psychology of workspace [34]. Managers, designers and workers in office buildings are seeking new ways to use this new knowledge 
to increase comfort and efficiency [5]. According to Vischer, it is vital to underline how "space is a resource and not just an expense to companies that learn how best to design workspace from the users' perspective" [6].

In recent years, there has been an increasing interest in the use of social robots in work environments and public spaces [22,35]. Therefore, recent trends in HRI have led to a proliferation of studies that are promoting the adoption of robots in places, such as shopping malls [36-38], banks, hotels, and companies' offices. In addition, the design of office spaces is facing a huge makeover in the last decade [1].

For these reasons, prior to proceeding with our investigation, it was important to review applications from different studies that could be significant for a systematic evaluation of a positive interaction with a social robot in public environments (Table 1).

Table 1. Summary of HRI studies in the work environment and public spaces mentioned in Section 2.3.

\begin{tabular}{|c|c|c|}
\hline References & Robot & Study Design \\
\hline Svenstrup et al., 2008 & FESTO & $\begin{array}{l}\text { Participants: } 48 \text { adults } \\
\text { No. of interactions: One-off interaction } \\
\text { Type: Autonomous } \\
\text { Measures: User experience } \\
\text { Evaluation: Questionnaires and interviews }\end{array}$ \\
\hline Kato et al., 2015 & Robovie & $\begin{array}{l}\text { Participants: } 26 \text { visitors } \\
\text { Conditions: Intention estimation algorithm vs. } \\
\text { proactive vs. non-adaptive } \\
\text { No. of Interactions: Field trail Interaction } \\
\text { Type: Autonomous with WoZ controlled speech recognition } \\
\text { Measures: Interaction intention success rate } \\
\text { Evaluation: Video analysis }\end{array}$ \\
\hline Liu et al., 2016 & Robovie & $\begin{array}{l}\text { Participants: } 33 \text { adults } \\
\text { No. of Interactions: One-off } \\
\text { Interaction Type: WoZ controlled robot } \\
\text { Measures: Naturalness, understandability, } \\
\text { perceived politeness and overall quality } \\
\text { of the robot's deictic behaviours } \\
\text { Evaluation: Questionnaire }\end{array}$ \\
\hline Gockley et al., 2005 & Valerie/irobot & $\begin{array}{l}\text { No. of interactions: On average } 88 \text { per day for } 9 \text { months } \\
\text { Interaction type: Chat-bot storytelling } \\
\text { Measures: Number of repetitive interactions, } \\
\text { time of each interaction } \\
\text { Evaluation: Log in data analysis }\end{array}$ \\
\hline Tonkin et al., 2018 & PAL REEM robot & $\begin{array}{l}\text { No. of interactions: } 200 \text { pieces of user feedback } \\
\text { Interaction type: Autonomous } \\
\text { Measures: Number of positive replies from the users, } \\
\text { Evaluation: Manual observations, questionnaires }\end{array}$ \\
\hline
\end{tabular}

One interesting study of HRI in public environments was carried out by Svenstrup et al. [39]. In their study, the researchers set up a field trial by installing a robotic platform called FESTO in a shopping mall. This social robot was given the task to track, identify and follow people inside the mall in a natural manner that should have been as least disruptive as possible for the customers who were visiting the shopping centre. The robot strolled around until randomly detecting a visitor, and then it started to play the jingle bell song. The robot stopped playing the music and started to follow the visitor after a given time [39]. This test included 48 participants and the findings showed that the visitors had an overall positive experience with the robot, since it was doing very simple tasks and was not really triggering any suspiciousness in the participants. However, some lamented the robot's ability to physically follow the people and other minor navigation problems. Another HRI 
field study that has been performed in a shopping mall is the one from Kato et al. [40]. In their study, the researchers used a robot called "Robovie" in order to perform and test three different behaviours:

- Robovie approached all the participants without distinction or preliminary estimation in the field test. - It then waited for the participants to start the interaction.

- Finally, it decided autonomously whether or not to approach the user based on the intention estimation of the interaction with the participants.

The findings showed that the participants enjoyed the third stage the most, i.e., when the interaction from the robot was both "passive" and "proactive". According to the participants, the robot's behaviour was perceived as more "natural" and likeable in the mixed behaviour stage since it had anthropomorphic features.

Similarly, Liu et al. [41] analyzed the behavioural implications between the same robot, Robovie, and the acceptance rate of the participants. Prior to analyzing the behavioural aspects, human-human interaction was observed and interviews have been performed in order to categorize three poignant behaviours:

- Gaze only,

- $\quad$ Precise pointing,

- Casual pointing.

After a preliminary stage of manual observations, a model for autonomously generating acceptable pointing behaviour was developed to be tested with the participants. This model allowed the robot to autonomously interact with humans by adopting one of the three proposed behaviours, according to the data obtained from the speech recognition and the user tracking system. The findings of this study highlight the general positive response from the participants who interacted with the robot, although some users pointed out difficulties in understanding the robot's interaction while it was pointing.

A significant analysis and discussion on the subject of behavioural interaction in HRI was presented by Gockley et al. [42]. In their study, they present a long-term social interaction between a social robot, Valerie the receptionist, and the occupants of the research facility at the Carnegie Mellon University. The investigation has been carried out for a total of nine months and the average number of daily interactors were 88 . The main task of the robot Valerie was to start a path of storytelling, usually a monologue programmed with a chatbot software with every person who approached it [42]. Participants had to log in with their ID college card in order to start to listen to the robot's monologues, and results highlighted that even after nine weeks since the experiment started and the "novelty effect" faded, a steady stream of visitors came to interact with the robot on a daily basis. Thus, we can assume that creating a simple daily interaction task can introduce a habit into a workplace that can last for a long-term period of time.

In a recent cross-sectional study, Tonkin et al. investigated whether the introduction of a social robot in a public space, such as an airport, could effectively help visitors performing their daily activities $[3,43]$. The field study was conducted over a span of two weeks, during which the robot was placed in a specific "needfinding" location previously established with the airport staff, in order to maximize the number of interactions and provide assistance with the passengers [3]. The first week was mostly devoted to the observation of the users and the quality of their interactions with the robot, while the second week the robot performance was reinforced with the feedback obtained from the first week's observations and subsequently more observations and questionnaires have been distributed among the passengers.

The findings from this study show that people were keen to interact with the robot; however, the humanoid aspect of PAL REEL triggered many expectations in passengers since they demanded that the robot performed more tasks beyond its abilities. Instead, the real tasks the robot was able to perform haven't been fully discovered from the users. This means that the appearance of the robot should reflect as close as possible its real capabilities and tasks that it is programmed for, in order to meet the expectations of the users and create a positive user experience. 


\subsection{Social Robots and the Telepresence Scenario}

In the last decade, the role of robots in ordinary life has gained momentum and, in the near future, the number of robots acting in contact with people will significantly increase. In addition, notably, service robotics is aiming to develop novel robotic solutions that could positively co-operate with human beings. In particular, a service robotics application as the Telepresence Robot provides a virtual presence to a remote location, using a video conference system. For this peculiarity, often this robot is called "Skype with wheels".

The Telepresence Robot is a particular type of robot that provides a virtual presence in remote locations. To generalize, the Telepresence Robot provides a connection between a user and a distant participant, to perform social interactions or specific tasks.

In Telepresence applications for interpersonal communication, there are two views: the user's and the participant's view. From the user's view, Telepresence enables the user to project himself/herself to another place by controlling the Telepresence Robot. In the meantime, the user perceives the immersion from the sensory feedback from the remote environment created by Telepresence.

For interpersonal communication, Telepresence differs from traditional video conferencing by establishing a true sense of shared space among geographically remote people.

All of the Telepresence Robot systems have common features:

- Motion system,

- Connection system,

- Video conference system,

- Sensors.

The motion system provides the ability to move the robot in the environment. In general, it is a wheeled robot remote-controlled by the user. The robot motion is provided by teleoperation or by autonomous navigation. With teleoperation, the user controls the robot using a dedicated application, it is a very simple operation, but it is not easy to move the robot inside a room and along a corridor using only on-board sensors and/or cameras. With autonomous navigation, the user is able to set the goal position on a map; then, the robot reaches the goal position autonomously, avoiding fixed and unexpected $[44,45]$.

The connection system provides the network connection. In general, an internet connection is required in order to communicate with remote locations. The internet connection is provided by wireless connection via LAN (Local Area Network) or mobile Internet technologies.

The video conference system manages the video call between user and participant. Commonly in this system, a simple tablet provides the video conference. On the user's side, the device should have a camera, a microphone and a speaker to provide an optimal communication.

Sensors perceive the environment in order to interact with it. The motion system requires sensors to detect and avoid obstacles and/or perform autonomous navigation. In addition, the video conference system requires sensors, such as cameras, speakers and microphones.

In a standard scenario, the user logs into the Telepresence Robot using a general device (computer, tablet or smartphone) via the Internet. In general, the access to the robot is allowed after this authentication. The user interacts with the remote environment by moving the robot and using sensors. Roughly speaking, the user is projected in the remote environment as a virtual presence, in which cameras are the virtual eyes, microphones the virtual ears, and speakers reproduce the user's voice. At the same time, the participant interacts with the robot that enables communication with the user by exchanging audio and video. Often, the Telepresence Robot transmits the video and audio received by the user's device, similarly to standard video conference applications.

\subsubsection{Telepresence Robot Commercial Applications}

Telepresence robots can be seen in different use cases [46]. In [47], the robot impersonates the user at work. In [46], the Telepresence robot system helps people with special needs; for example, 
seniors and people with disabilities can use the Telepresence robot to contact friends and family, or to work from remote locations. In [48], the authors propose the Telepresence robot for home care assistance [49], while, in [50], the system is used for English tutoring.

The potential of the Telepresence robot system has allowed the development of a number of Telepresence robot platforms, i.e., Giraff Technology's Giraff [51], Anybots' QB 2.0 [52], VGo Communications' VGo [53], Willow Garage's Texai [54] and Double Robotics' Double2 [55], to cite a few.

\subsection{Navigation Challenges in a Physical Space, Ethics and Privacy Related to Telepresence}

The majority of ethical issues afflicting robotic telepresence applications concern user privacy and safety. Physical safety issues are quite obvious, as the robot is a heavy mobile object controlled by someone who is not physically present. Depending on the quality and quantity of sensors available on the robotic platform, the operator might not be completely aware of its surroundings. The risk of breaking objects or harming human beings is not negligible. It is even possible for the robot itself to incur damages (e.g., falling down the stairs). The risks increase when the robot is introduced to a dynamic environment, i.e., not every object around the robot is stationary. If the robot is operating in crowded areas, the probability of colliding with others increases.

A second set of important issues are those related to privacy. Within this context, privacy must be considered in two different facets: privacy of the users participating in the communication from the rest of the world (hereby "external" privacy), and privacy of the owner of the Telepresence robot from its potential users ("internal" privacy).

External privacy is the expectation that the conversation between users of a telepresence application is private and cannot be intercepted by third parties. This also implies having the certainty that the peer in the communication is in fact who she claims to be (i.e., authentication). These are the same issues that afflict classic teleconferencing applications, like videochat or even the telephone.

More interesting are the issues regarding internal privacy. Having a mobile robot, equipped with a camera, inside one's own house, poses a lot of concerns. The obvious one is: who can access the robot? Giving a user access to the telepresence application is the equivalent of inviting them inside one's own house. Technically, the robot could go and look everywhere. Even assuming that the owner can control who can use the robot, there is the more concerning possibility (always present) of unauthorized access (e.g., from a hacker).

Additionally, the robot may collect data necessary for its correct functioning (e.g., map of the environment). It is not possible to avoid collecting this data, as it would compromise the robot's correct operation. This data might contain sensitive information, and therefore must be kept secure.

\section{Methodology}

A case study approach was adopted to gain a detailed understanding of this research context. The used methodology is the result of the combined application of the research through design approach [56], the UX Usus model from Weiss et al. [17] and the Alenjung et al. UX integrate method applied to HRI [12]. The experiment was set up in order to follow a lean UX design, which could be adaptive to different needs, but, at the same time, the tasks the robot had to perform should not be overly complicated or too obscure to be understood by the users.

\subsection{Define the Challenges and Observations}

In the beginning, it was essential to focus on the users' requirements in order to put forward a practical methodology for firstly identifying viable, and potentially commercial, applications for a social robot in a specific environment as a company workspace. The aim of the study was to comprehensively design the user experience for the robotic application that could easily merge in that given environment $[57,58]$. Subsequently, two issues related to HRI started to be defined: 
- Identifying viable applications for social robots,

- Determining how to create a positive user experience in a specific environment that could be replicable in other contexts.

These issues emerged from the observation of the specific context, where the experiment would have been performed. In order to perceive and experience the social context, the observation took place in specific "needfinding" locations inside the company's building, such as the entrance gate and the reception. The research team has been timing these observations in precise moments of the day, while the reception's staff stated a major congestion of the entrance from the visitors. The members of the research team also actively asked feedback from visitors and the staff with the aim to better empathise with the environment. The interviews included the following questions:

- How do you perceive the current visiting experience?

- What would you like to change about the location/experience?

- How do you rate a good experience as a visitor/staff member?

Subsequently, a customer journey map (Figure 1) has been developed thanks to this preliminary feedback, and it acted as a base for a more detailed future customer experience.

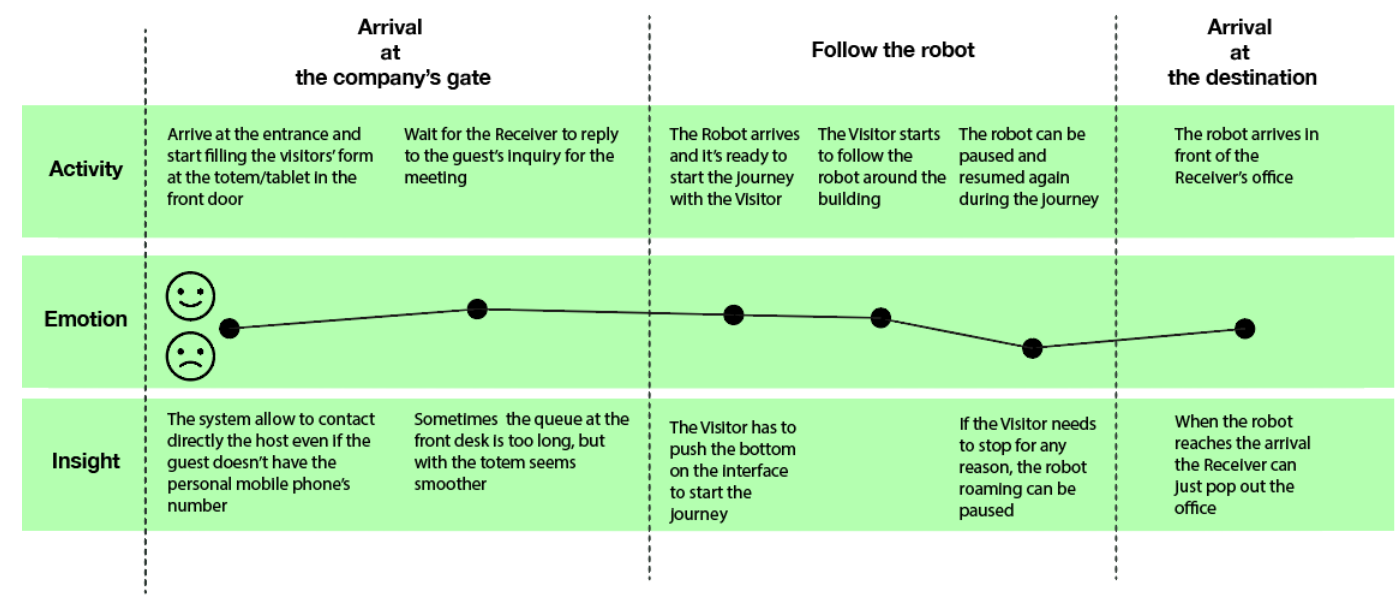

Figure 1. Example of the customer experience in the building, recreated after the findings of the workshop performed with the employees in the company's building and the robot's developers.

\subsection{Preliminary Requirements}

Since this study was conducted in a exploratory approach, at first, it was vital to introduce a preliminary phase where the users' requirements emerged and subsequently have been systematically organised for a structured designing process. In order to investigate the users' needs, a focus group has taken place. The focus group consisting of eight participants was held in the meeting area of the telecommunication company where the field study would have been subsequently performed. In order to identify the requirements and the needs, the participants were asked to actively support the group discussion led by the investigator. The direct evidence about similarities and differences in the participants' opinions and experiences generally favoured a robot companion helper in their office environment. Most of the participants were full time employees, except for two people who participated in the manufacturing of the prototype of the robot. The insights that emerged from the participants' discussion suggested that:

- The robot should be a companion, and perform simple tasks that anyone can address and understand since the age range in between the employees spans from $29 \mathrm{y} / \mathrm{o}$ to $65 \mathrm{y} / \mathrm{o}$, and perhaps there could be some difficulties in the use of novel technologies

- The most time-consuming task during the day is to go up and down the floors of the company building in order to gather guests for the meetings coming from other sub-offices or from other towns 
- The blueprint of the building itself is very intricate, and even with many directions given in advance, there's a high chance to get lost or to spend more time in wayfinding

- Some robots have already been tested before in the same building, but, after the first few days, employees lost their interest due to the lack of novelty and an interface that is not very user-friendly

- The previous tested robot was a humanoid, a Nao, and people resulted in having high expectations in its abilities or, on the contrary, they simply perceived it as an expensive toy

\section{Designing the Service and the Robot}

Designing a social robot for a specific public environment, such as a company workspace, was challenging because of the different variables involved in the process [59]. In order to develop a contextually appropriate robotic technology, it is vital to take into account many parameters, such as:

- Usability,

- Usefulness,

- Flexibility,

- Likeability,

- Utility.

The data collected during the observations and the focus group have led to the creation of a proper storyboard of the service, in order to understand every single step in which the robot should perform the given tasks, Figures 2 and 3. These storyboards were generated to provide supportive insights for the design of the robot's App and its functionalities. The robot courier functionalities have been designed to minimise the user's discomfort during the experience and to analyse in detail each step that would lead to a specific task. The design of the service provided by the robot is intended to perform simple tasks that cannot mislead the users to different actions and expectations towards the robot.

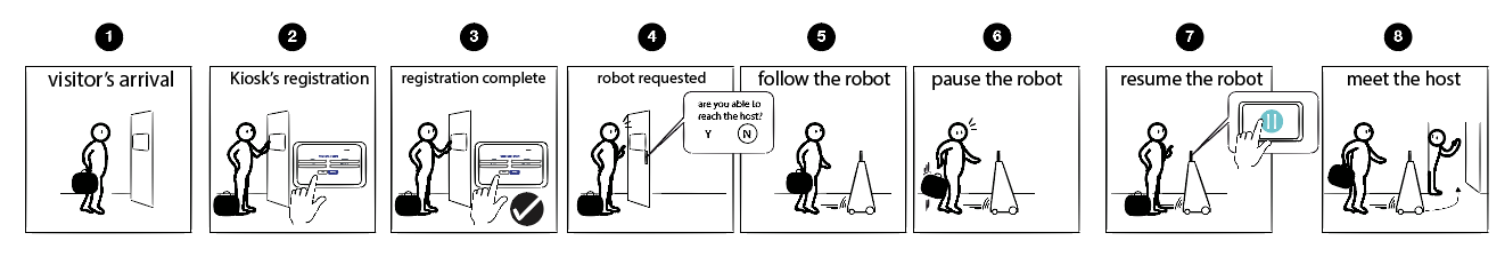

Figure 2. The user experience storyboard involving the Visitor and Receiver characters.

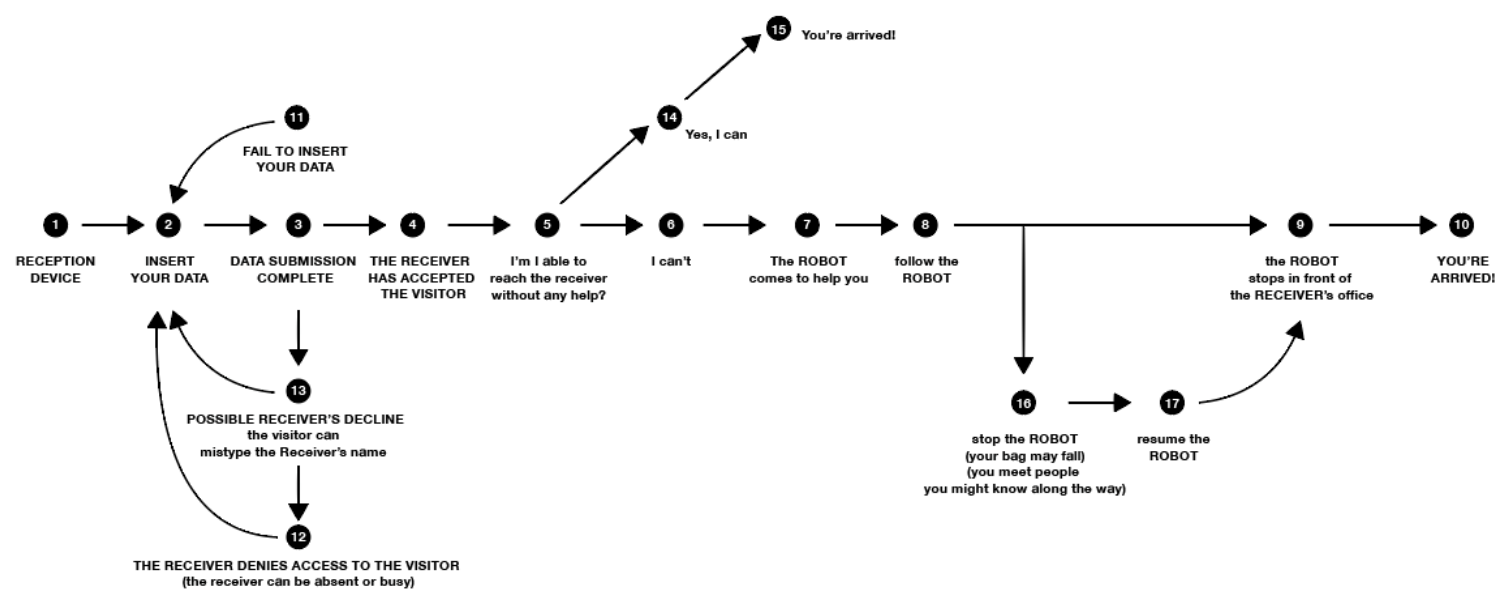

Figure 3. The Robot courier service text storyboard created to define the path it has to follow. 


\subsection{Designing the Service}

Immediately after the analysis of the customer journey (Figure 1) and the iterative (storyboard Figures 2 and 3), it was essential to define which technology could have been employed in order to better fit the tasks the robot courier needed to perform. Essentially, the main task of the robot was to pick up visitors at the entrance hall/gate of the company's building and accompany them to the designed office, where the receiver was waiting for them. In order to welcome the visitors at the entrance, a self service kiosk has been installed in the main entrance. This kiosk uses a tablet, where an interface has been designed to gather the visitors' data and subsequently contact the robot for the pick up. The incoming visitors had to fill in the form provided in the tablet's kiosk and confirm their identity. Afterwards, if they didn't know the location of the office of the receiver or the precise room to reach in the building, the robot courier was arriving in a brief time at the meeting point next to the kiosk. Then, at the arrival, the robot courier displayed a tablet on the very top, where the interface of the kiosk was mirrored but then started to give directions to the visitor in order to reach the desired meeting point. In the meantime, the receiver in the company office was able to accept the incoming visitor at the kiosk thanks to a mobile App running on the smart phone. The App was designed to give notice to the receiver of the visitor's arrival, with the details received in the subscription form. In this way, the receiver would have been aware of the guest arriving and decide to welcome him/her and, in that case, send the robot to show the way to his/her office. Thus, the interface running for providing an optimized experience essentially consisted of three parts: the tablet in the kiosk, the tablet above the robot courier, and on the smart phone of the receiver inside the company's building as depicted in Figure 4.
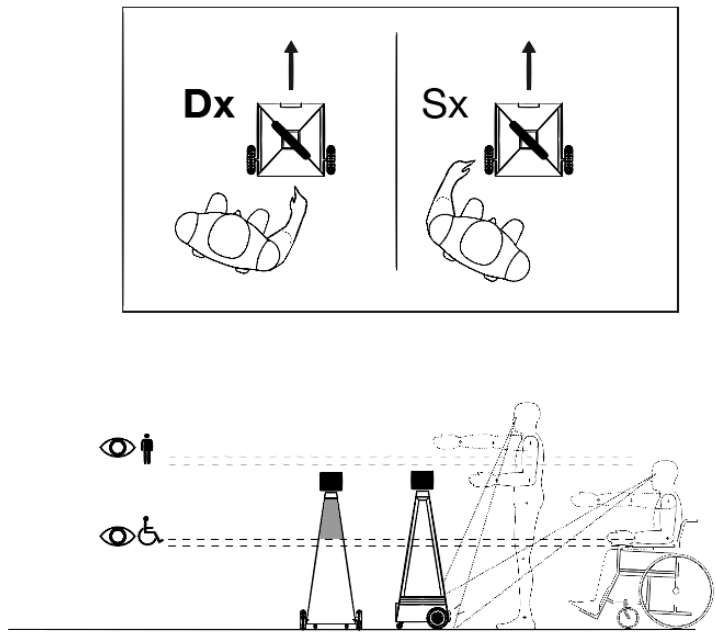

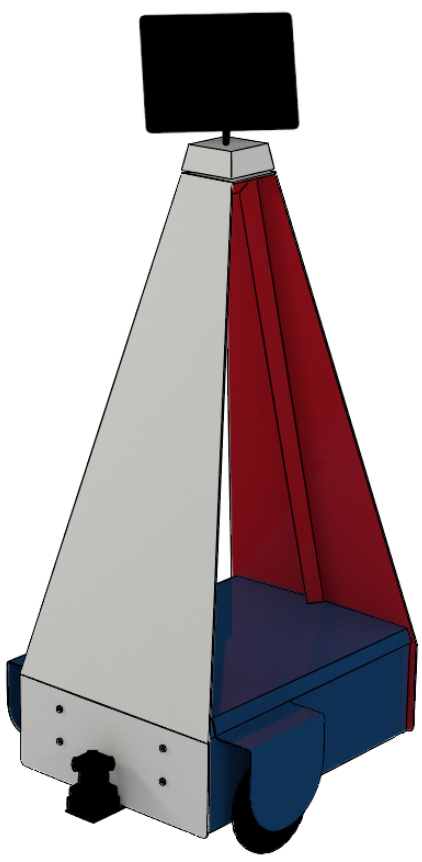

Figure 4. The general appearance of the robot is designed to be integrated into the building's lobby, and resemble part of the architecture. The colours chosen are the official ones used from the company's brand. The robot has been designed to support ergonomic aspects that take into account accessibility and affordance.

\subsection{Acceptance and the Limits of Anthropomorphism}

According to Dautenhahn [20], the concepts of perception and acceptance are central to HRI, since it is crucial for human partners to interact with the agents in an intuitive way. In the context where the social robots are used, especially in the case of social robots, they have to support people in 
everyday activities and perform tasks that are simple [60,61]. In order to design socially interactive robots, it is important that the tasks they can perform can be grasped as fast and intuitively as possible by the humans. For example, in the study presented by Sakamoto et al. [62] that involved a humanoid robot as a telepresence agent, the user expected more the machine to have more skills due to its anthropomorphic aspect, and inevitably they showed signs of frustration when the robot couldn't perform the expected tasks $[63,64]$. Therefore, the robot courier was designed to be able to perform the tasks that were expected by the users. With the aim to accomplish these guidelines, the robot courier was designed in such a way that its appearance was not particularly anthropomorphic, but had more of a geometric shape.

\subsection{Designing the Robot Courier}

Affordance is a commonly-used notion in psychology and yet it is a concept difficult to define precisely. It has been extensively used in HCI and interaction design at large, and puts an accent on everyday objects with their attendant features and functions $[65,66]$. The perceived possible actions that an object can suggest by its appearance are vital in order to define a smooth human-robot interaction, referring to how an object may be interacted with [67]. For this reason, the perceived utility and usability of a social robot should completely reflect the tasks it can perform and those it cannot. Therefore, the robotic agent should express by its appearance its abilities, adopting specific aesthetic ethics that could fit in a given context.

\section{The Limits of Anthropomorphism and Adaptation to Context of Use}

According to Masahiro Mori [68], the robot's level of expressiveness cannot just be defined by the degree of humanisation of it, but to some extent by the ability and the fluidity of its movements and the capacity of completing the tasks demanded by the users [69]. In order to pursue an enhanced user experience, the appearance of the robot courier was designed to be far from an anthropomorphic shape. To meet the users' expectations, the shape of the robot is the result of a formal synthesis that was brought from the idea of a social companion that is part of the environment; in this case, a company's workspace building. The design was inspired by the generation of robot applications for home care assistants, such as the Roomba [70,71]. This specific robot gives a peculiar sense of familiarity [72] to the users, who are associating this machine more to a domestic appliance rather than a robot. Therefore, the acceptance rate of the Roomba is high, since people are often giving it a name or even assigning it a personality $[73,74]$.

The semblance of the last generation of cleaning robots introduced among users a familiarity towards social robots, which can hopefully be adopted in other contexts and promote a transition from anthropomorphic aspects towards the adoption of more synthetic lines and abstraction aesthetics. These geometrical and more synthetic aesthetics would promote a better integration of social robots in more viable contexts of use [73].

\subsection{Ergonomic Considerations and Functionalities}

The control of the robot is designed to be autonomous and assure a smooth navigation in response to the interface stimuli $[75,76]$. For this purpose, the robot presents a tablet screen on top of a mobile wheeled platform than can be addressed from the designed points of interest both from a kiosk at the building's entrance and from a mobile App running on the employers' mobile phones [77]. The cover on top of the mobile platform is assembled into a truncated pyramid shape, making a visual connection with the building interiors and using the company's official colours. The material chosen for the shell is aluminium, since it supplies the need of a better stability, in order to achieve a minor oscillation on the robot's top part, where the tablet is located. The robot courier's design is strictly bonded to the architecture of the building, responding to a desire to blend the social robot with other architectural elements or furniture present in the lobby. The robot should not gather the users' whole attention since it is designed to accomplish specific assisting tasks and can be customized based on different contexts 
of use. The tablet on top of the robot is placed diagonally, with the aim of being used from both right and left handed users. The height and the shape of the robot itself is ideal to promote accessibility both for wheelchair users and non-disabled users.

\subsection{User Interface and GUI}

With the aim of enhancing the intelligibility of the user interface running on the tablet on the robot, on the self service kiosk, and on the Mobile App, the graphic layout was inspired by the Material Design proposed by Google in [78]. To achieve an improved intelligibility and minimize the time to train the people to approach the user's interface, all of the actions take place in a single environment [78]. The objects in the screen appear without breaking the continuity of experience even as they transform and reorganize [78]. The whole layout design respects the grids and the spacing optimized in the Material Design for balancing information density and usability as depicted in Figures 5 and 6.
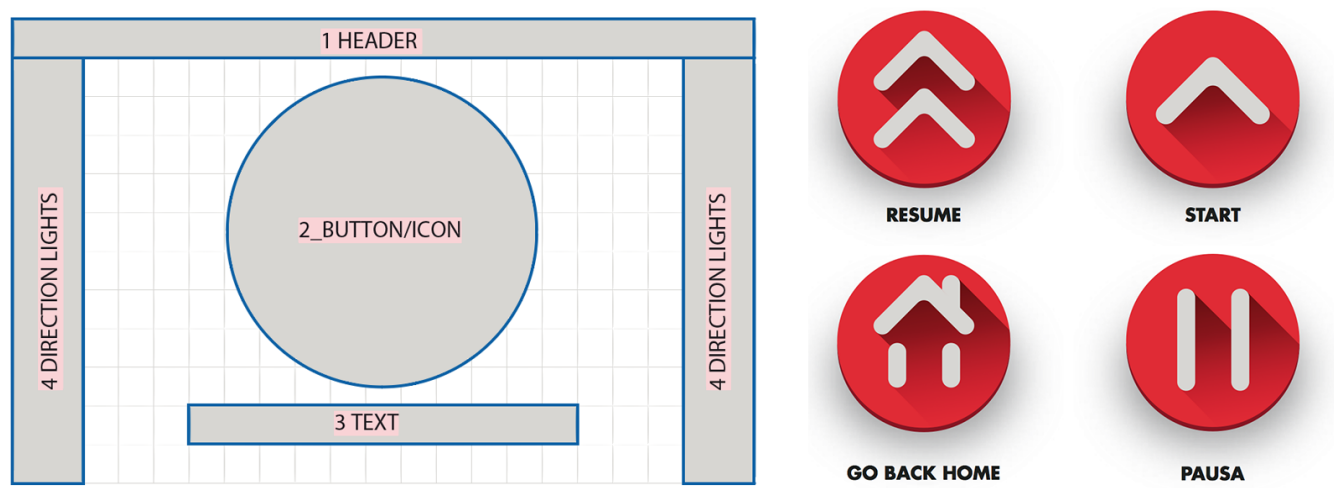

Figure 5. In the screen grid, the elements correspond to: 1-the header, which host the logo and the company layout, 2-the maximum area dedicated to the button, 3-brief text to explain the button function if needed, and 4-the direction of lightening that provides an easier way to understand the robot's path. On the right side of the picture, we can see some icons created for the graphic layout.
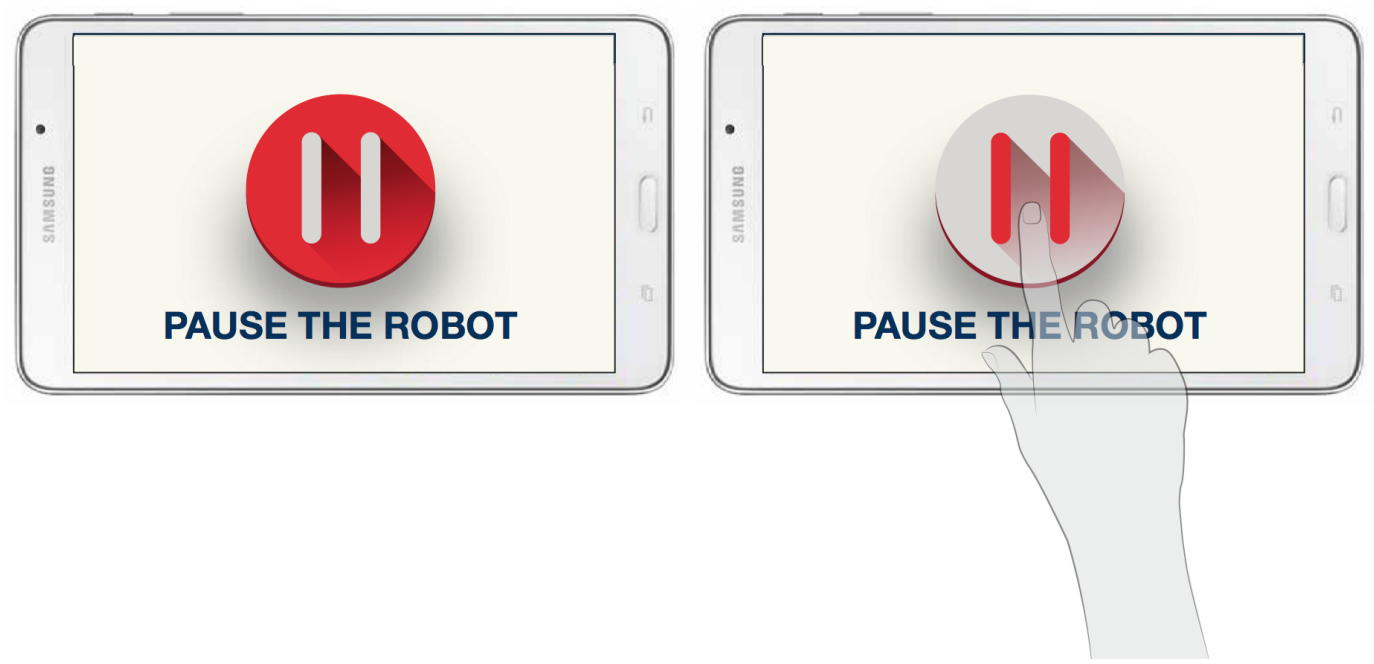

Figure 6. During the navigation, the tablet above the robot provided the option of being momentarily paused and subsequently resumed.

\subsection{Supplementary Material Test-Field Study Description}

The field study with the robot courier was conducted in order to explore and evaluate the five parameters previously mentioned in Section 4, and therefore to implement the user experience with 
the social robot [79]. After the findings from the workshop and the feedback from the observations which defined the preliminary results, a period of two weeks has been set in order to allow the robot time to complete its task performing period. During these weeks of field study, the robot performed, on average each day, five trips and escorted 48 people to specific destination points. The robot was activated in precise time spans when the reception was, on average, more congested, between 10:00 a.m. to 12:00 p.m., and between 2:00 p.m. to 4:00 p.m. The participants were selected at the entrance door, where the self service kiosk with the tablet was placed. Subsequently, each participant started the navigation path with the robot, consisting of three main steps as depicted in Figure 7:

- $\quad$ Step 1-Reception phase,

- $\quad$ Step 2-Elaboration phase,

- $\quad$ Step 3-Navigation phase.

At the end of the Navigation phase, a questionnaire was delivered to each participant in order to evaluate the experience with the robot.

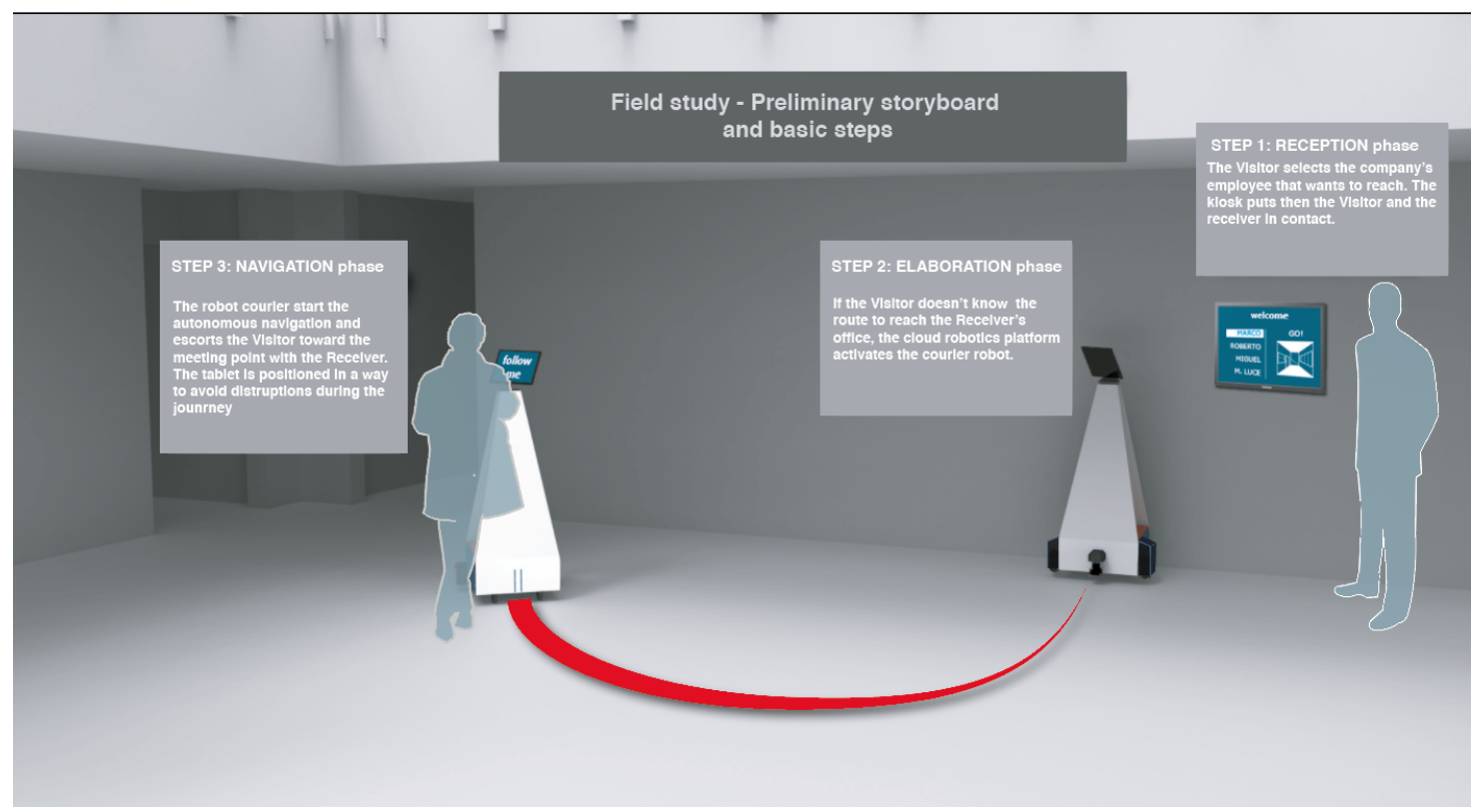

Figure 7. The three basic steps that defined the major moments of the field study for the evaluation process.

\section{Evaluation}

The test was firstly aimed at observing both usability and user experience aspects. The study was meant to test the actual increased comfort and related experiences, such as usability and likeability. In an attempt to understand the emotional experience of users $[80,81]$, a combination of observations and user questionnaires has been used.

\section{Qualitative Analysis of Participant Responses to the Questionnaires}

To explore the users/participants attitude towards the robot courier, a Godspeed questionnaire was used, which includes a Likert scale to quantify the engagement, acceptance, and affordance of the single users [82]. The survey was composed of 34 questions and distributed to 48 participants as reported in Figure 8. The questionnaire was helpful to refine the data related to the robot evaluation since a wide range of variables referring to cognitive and socio-cultural factors, such as education, life and work conditions, attitude towards technology, and forms of attachments can determine the way people approach and behave with robots $[17,83]$. In addition, the questionnaire was helpful in order to investigate other evaluation variables, such as the social acceptance impact, which are always pivotal to HRI studies [84,85]. 
The project's evaluation presented in this paper was performed in the attempt of providing insights into the general parameters presented at the beginning of Section 4. A particular attention was devoted to measure the perceived robot's likeability, in the ways that the robot can be perceived as a positive improvement in the daily life in the office space, and perceived intelligence. The perceived intelligence factor was crucial to understand how the robot can be compatible with the context of use, which can be helpful to identify the potential users' values and beliefs [84].
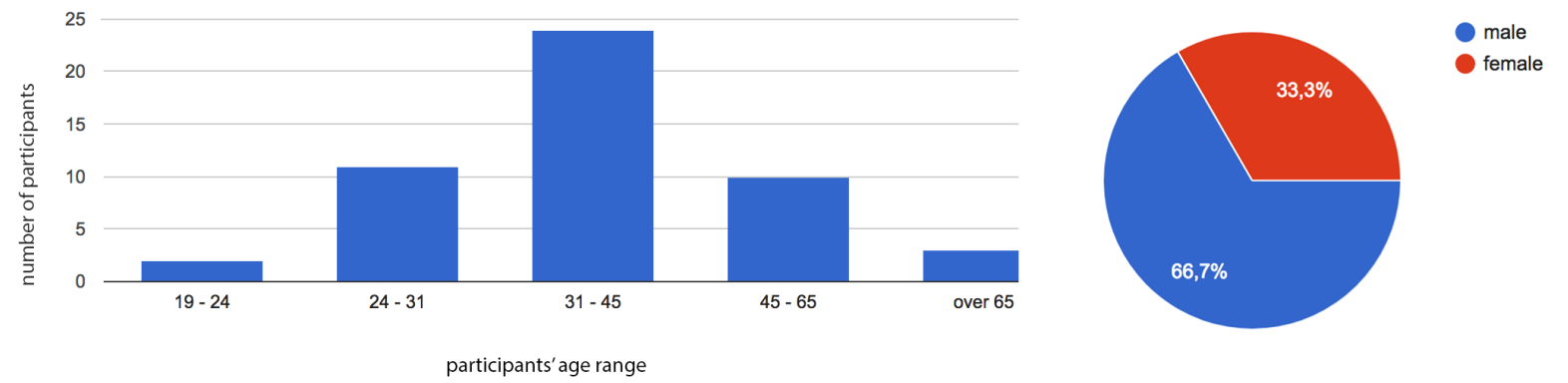

Figure 8. Demographics of the participants. Out a total number of $48,66.7 \%$ was male and $33 \%$ was female. The prominent age span was between 31 and $45 \mathrm{y} / \mathrm{o}$.

\section{Findings and Results}

The project's evaluation presented in this paper was performed in the attempt of providing insights into the general parameters presented at the beginning of Section 4. Furthermore, the questionnaire was helpful in investigating the relationship between a non-anthropomorphic robot and its own level of likeability and acceptance. From the findings reported in Table 2, it is possible to observe how the grade of acceptance is generally quite high despite the perceived appearance of a machinelike agent $(\mathrm{Av}=2.32$ with a $\mathrm{SD}=0.75)$ with artificial traits $(\mathrm{Av}=3.31$ with a $\mathrm{SD}=0.97)$. Alongside the Godspeed questionnaire, it was vital to pair the survey with on-site observations that have shed light on why, even if the movement of the robot is not perceived as "very elegant", the likeability of the robot is still high. According to the participants, "it was more important to have a robot who could move while performing the specific given task, rather than one that moves more fluidly but doesn't perform the instructed task". Moreover, this perception of likeability is reinforced by the appeal of the user interface since, "Using an easy to use graphical interface makes me feel at ease with the robot, and I perceive it more like a companion, such as the Roomba". The ability of the robot courier to perform specific tasks has been perceived positively, and has gained a high grade of competence ( $\mathrm{Av} 4.00)$. In conclusion, the results suggest that, in order to reach a positive experience, the robot companion has to express its intentions and skills as clearly as possible, in order to avoid unmet expectations. 
Table 2. The table presents the average (Av) and the standard deviation (SD) of the variables taken into account in the survey tested parameters.

\begin{tabular}{cccc}
\hline Attribute & Category & Av & SD \\
\hline \multirow{3}{*}{ Anthropomorphism } & Humanlike & 2.32 & 0.75 \\
& Non-Artificial & 3.31 & 0.9 \\
& Moving Elegantly & 3.17 & 0.79 \\
\hline Animacy & Lively & 3.92 & 0.74 \\
\hline \multirow{2}{*}{ Likeability } & Friendliness & 4.33 & 0.75 \\
& Pleasantness & 4.25 & 0.70 \\
& Niceness & 4.27 & 0.74 \\
\hline \multirow{3}{*}{ Perceived Intelligence } & As Competent & 4.00 & 0.68 \\
& As Knowledgeable & 4.00 & 0.62 \\
& As Responsible & 3.85 & 0.68 \\
\hline \multirow{3}{*}{ Safety perceived before the test } & Anxious/Relaxed & 2.13 & 0.64 \\
& Calm/Agitated & 1.96 & 0.82 \\
& Quiescent/Surprised & 2.19 & 0.84 \\
\hline \multirow{3}{*}{ Safety perceived after the test } & Anxious/Relaxed & 4.42 & 0.50 \\
& Calm/Agitated & 4.42 & 0.54 \\
& Quiescent/Surprised & 4.31 & 0.51 \\
\hline
\end{tabular}

\section{Discussion}

In recent years, robotics applications for industrial, military and medical fields have flourished and become more and more prominent. In the meanwhile, service robotics and social robot applications have become increasingly popular due to the attention of the HRI and, even more recently, the collaboration of the HCI and UX design methodologies. To develop a full picture of viable HRI applications, service and personal robots will move and act in dynamic and unpredictable environments, and will be employed and driven by untrained users $[73,86]$. Prior to a large scale distribution of social robots, it is vital to depict the conditions that can increase the acceptance rate of robots in human society, in order to improve a viable coexistence with users in everyday life. With the aim of easing the acceptance rate of the society towards a HRI extensive application, it is important to hedge unsuccessful competitive situations since the diffusion of increasingly autonomous robots "will drive a shift from a condition where man possesses and controls robots to a coexistence condition where robots are semi-autonomous" [73]. Furthermore, the acceptance is intended in a more complex level if we take into account the correlation with existing social practices and the expressive clarity that makes the technology easily recognisable $[87,88]$. According to Walters, usability, safety, costs and the physical appearance of the robot can undertake a lead position [68], since these factors can play a role on a cognitive experience with the users [89]. In addition, the findings show that is possible to say that there has been no correlation between specific age span groups and the perceived safety before and after the experiment. In addition, no significant correlation was found between the participants' gender and the acceptance rate, in contrast with the studies of Schermerhorn and Kuo [90,91].

\subsection{Robot Courier Implications}

This work contributes to the existing knowledge of HRI by providing insights on how an autonomous social robot can be perceived in a specific context, and how the effects of the perceived intelligence and likeability could ease social robots' integration in daily life [92,93]. In this paper, the design, and subsequently the evaluation, of the robot courier, a non anthropomorphic companion specifically designed to interact with people and complete simple automated tasks, has been described. The range of expressive motions of the robot was very limited, and its appearance has been rated as "machine-like", as shown in Table 2, but nevertheless the likeability rate and the safety perceived after the test received generally positive results. These results can suggest that practical considerations to 
design social robots should include a deep investigation of a precise scenario, and, even if the robot is not able to perform high cognitive tasks, as long as it could complete the tasks that it is designed for and the people can make a quick interpretation of its skills, the acceptance rate towards the robot courier can still be quite high. However, even if the robot completes the tasks in an inadequate manner, or fails to carry out the tasks altogether, the situation could lead to a more positive perceptions of the robot after all, as if compared to a robot that does not move at all.

The results stated in this study emphasise that:

- The powerful role that the robot's movements and responsiveness could in general have a positive influence on participants' perception of the robot,

- That a simplified user interface can play a key role in enhancing the positive attitude towardss a non-anthropomorphic robot.

Therefore, it is possible to assume that, even if the robot is not supported by a high cognitive technology, it can still be perceived positively by the users. This positive perception can persist even when the robot doesn't perform the tasks at its best. The findings show that, if the robot's behaviour can be interpreted as coherent and goal-directed, even if it does not conform to what would be expected of socially engaging behaviour, "it still facilitates the human propensity to ascribe intentions to agents" [82].

\subsection{Ethics Considerations, Stakeholders and Privacy}

This study adds to the growing body of research that indicates that physical safety issues are addressable through technological solutions. The robot itself should be designed to be well visible. Every time the robot courier moves, or is about to move, it should provide some form of feedback to the surrounding people (e.g., lights, sounds, user interface response) [94]. These adjustments will improve the people's interaction with the robot and secure a way to avoid physical damage. At the same time, the robot should be able to avoid collisions itself, either against static obstacles or other people [95]. This can be done in two steps: first, the robot must be equipped with a sufficient number of sensors to be able to detect potential obstacles or other hazards in its surroundings. Then, its control software must implement a set of fail-safes that take over in case the user is driving the robot towardss a potentially dangerous situation. It should be impossible for the user to force the robot to cause harm either to itself or to other people.

Privacy issues are harder to solve perfectly, but there are lots of precautions one can take to avoid them as much as possible. External privacy issues are largely addressed already in the context of classic teleconferencing software (e.g., videochat). Any data exchanged by the users must be encrypted and authenticated. The owner of the robot, in particular, must know with certainty the identity of the peer. This is closely tied with the internal privacy issues. From a software point of view, the owner of the robot must be able to configure, at a minimum, a set of authorized users. However, not every user might have the same privileges. The configuration possibilities should be extremely fine grained. The owner should be able to control, among other things: who can access the robot, at what times, what capabilities of the robot that he/she can use (camera, movement), where the robot can go, etc. These controls can be implemented in software, but they are not a perfect solution.

The possibility of unauthorized access is always present. Software security can be circumvented. Having a robot equipped with a camera inside one's own house can be a great security problem if that robot can be accessed by malicious people. Therefore, it is necessary to provide security solutions implemented in hardware. The obvious one is to provide a master switch that effectively cuts off the robot from its power source. This would ensure the owner that nobody, whether they are authorized or not, can use the robot until switched on again. Additionally, the robot should feature finer-grained hardware controls, such as the ability to disable only movement and not the camera.

With regard to data collected by the robot for its routine operations (e.g., map of the environment), designers of the robot must ensure that this is not accessible from the outside. One possibility is to 
provide a separate storing device, only accessible by the robot. To avoid unauthorized access, the core code of the robot should be digitally signed and its validity checked (possibly in hardware) every time it is started.

These potential solutions highlight the underlying trust issue: the owner of a Telepresence robot must, implicitly, trust at least one party (the hardware manufacturer of the robot). The only way to avoid this would be to release publicly the hardware specifications, allowing the users to verify for themselves. Still, there is no guarantee that the robot does in fact implement those specs.

\section{Conclusions and Future Works}

Further work is required to establish the viability of the better application of social robots in everyday life. Despite these promising results, questions remain, and a variety of different scenarios can be tested in order to generate a database for these types of situations. This does not just imply the use of a robot companion efficiently in a office space, but also many other scenarios to be evaluated. The results of this study support the iterative evaluation methods from UX and HCI studies, and they showed an increased benefit and potential application for further investigations. Overall, the results depict that a social robot, even in situations where the robot is not directly performing a specific task, can adopt a behaviour that has a significant impact on the overall enhancement of the user experience of the robot.

Author Contributions: This project was carried out by S.K. as primary investigator, who designed the field study. C.G. advised and revised the whole phases of the project.

Funding: This work was supported by a fellowship from TIM (Telecom Italia Mobile).

Conflicts of Interest: The authors declare no conflict of interest.

\section{Abbreviations}

The following abbreviations are used in this manuscript:

$\begin{array}{ll}\text { HCI } & \text { Human-Computer Interaction } \\ \text { HRI } & \text { Human-Robot Interaction } \\ \text { UX } & \text { User Experience } \\ \text { WoZ } & \text { Wizard of Oz }\end{array}$

\section{References}

1. Wells, M.; Thelen, L. What Does Your Workspace Say about You?: The Influence of Personality, Status, and Workspace on Personalization. Environ. Behav. 2002, 34, 300-321. [CrossRef]

2. Hoffman, G.; Breazeal, C. Effects of anticipatory action on human-robot teamwork efficiency, fluency, and perception of team. In Proceedings of the ACM/IEEE International Conference on Human-Robot Interaction, Washington, DC, USA, 9-11 March 2007; pp. 1-8.

3. Tonkin, M.; Vitale, J.; Herse, S.; Williams, M.-A.; Judge, W.; Wang, X. Design Methodology for the UX of HRI: A Field Study of a Commercial Social Robot at an Airport; ACM Press: New York, NY, USA, 2018; pp. 407-415.

4. Goodrich, M.A.; Olsen, D.R. Seven principles of efficient human robot interaction. In Proceedings of the 2003 IEEE International Conference on Systems, Man and Cybernetics, Washington, DC, USA, 8 October 2003; Volume 4, pp. 3942-3948.

5. Vischer, J.C. Towards an Environmental Psychology of Workspace: How People are Affected by Environments for Work. Archit. Sci. Rev. 2008, 51, 97-108. [CrossRef]

6. Vischer, J.C. Space Meets Status Designing Workplace Performance; Routledge: London, UK, 2005; ISBN 978-0-203-08777-0.

7. Marder-Eppstein, E.; Berger, E.; Foote, T.; Gerkey, B.; Konolige, K. The Office Marathon: Robust navigation in an indoor office environment. In Proceedings of the 2010 IEEE International Conference on Robotics and Automation, Anchorage, AK, USA, 3-7 May 2010; pp. 300-307. 
8. Rosenthal-vonderPütten, A.M.; Krämer, N.C.; Hoffmann, L.; Sobieraj, S.; Eimler, S.C. An Experimental Study on Emotional Reactions Towards a Robot. Int. J. Soc. Robot. 2013, 5, 17-34. [CrossRef]

9. Alavinia, S.M.; Molenaar, D.; Burdorf, A. Productivity loss in the workforce: Associations with health, work demands, and individual characteristics. Am. J. Ind. Med. 2009, 52, 49-56. [CrossRef] [PubMed]

10. Joosse, M.; Lohse, M.; Evers, V. Short Duration Robot Interaction at an Airport: Challenges from a Socio-Psychological Point of View. In Proceedings of the 5th International Conference on Social Robotics, Bristol, UK, 27-29 October 2013.

11. Triebel, R.; Arras, K.; Alami, R.; Beyer, L.; Breuers, S.; Chatila, R.; Chetouani, M.; Cremers, D.; Evers, V.; Fiore, M.; et al. SPENCER: A Socially Aware Service Robot for Passenger Guidance and Help in Busy Airports. In Field and Service Robotics; Wettergreen, D.S., Barfoot, T.D., Eds.; Springer International Publishing: Cham, Switzerland, 2016; Volume 113, pp. 607-622, ISBN 978-3-319-27700-4.

12. Alenljung, B.; Andreasson, R.; Billing, E.A.; Lindblom, J.; Lowe, R. User experience of conveying emotions by touch. In Proceedings of the 2017 26th IEEE International Symposium on Robot and Human Interactive Communication (RO-MAN), Lisbon, Portugal, 28 August-1 September 2017; pp. 1240-1247.

13. Hartson, R.; Pyla, P. S. The UX Book: Process and Guidelines for Ensuring a Quality User Experience; Elsevier and Morgan Kaufmann: Amsterdam, The Netherlands, 2012; ISBN 978-0-12-385241-0.

14. Goodrich, M.A.; Schultz, A.C. Human-Robot Interaction: A Survey. Foundations and Trends. Hum. Comput. Interact. 2007, 1, 203-275. [CrossRef]

15. Lindblom, J.; Andreasson, R. Current Challenges for UX Evaluation of Human-Robot Interaction. In Advances in Ergonomics of Manufacturing: Managing the Enterprise of the Future; Schlick, C., Trzcielinski, S., Eds.; Springer International Publishing: Cham, Switzerland, 2016; Volume 490, pp. 267-277; ISBN 978-3-319-41696-0.

16. Lee, M.K.; Forlizzi, J. Designing adaptive robotic services. In Proceedings of the International Association of Societies of Design Research 2009, Seoul, Korea, 18-22 October 2009.

17. Weiss, A.; Bernhaupt, R.; Lankes, M.; Tscheligi, M. The USUS evaluation framework for human-robot interaction. In Proceedings of the AISB2009, Symposium on New Frontiers in Human-Robot Interaction, Edinburgh, UK, 6-9 April 2009; Volume 4, pp. 11-26.

18. Luber, M.; Arras, K. Multi-Hypothesis Social Grouping and Tracking for Mobile Robots. In Proceedings of the Robotics: Science and Systems 2013, Berlin, Germany, 24-28 June 2013.

19. Baxter, P.; Kennedy, J.; Senft, E.; Lemaignan, S.; Belpaeme, T. From characterising three years of HRI to methodology and reporting recommendations. In Proceedings of the 201611 th ACM/IEEE International Conference on Human-Robot Interaction (HRI), Christchurch, New Zealand, 7-10 March 2016; pp. 391-398.

20. Dautenhahn, K. Socially intelligent robots: Dimensions of human-robot interaction. Philos. Trans. R. Soc. $B$ Biol. Sci. 2007, 362, 679-704. [CrossRef] [PubMed]

21. Lee, M. K.; Kiesler, S.; Forlizzi, J. Mining Behavioral Economics to Design Persuasive Technology for Healthy Choices; ACM Press: New York, NY, USA, 2011; p. 325.

22. Ahmad, M.; Mubin, O.; Orlando, J. A Systematic Review of Adaptivity in Human-Robot Interaction. Multimodal Technol. Interact. 2017, 1, 14. [CrossRef]

23. Leite, I.; Martinho, C.; Paiva, A. Social robots for long-term interaction: A survey. Int. J. Soc. Robot. 2013, 5, 291-308. [CrossRef]

24. Tapus, A.; Mataric, M.J.; Scassellati, B. Socially assistive robotics [grand challenges of robotics]. IEEE Robot. Autom. Mag. 2007, 14, 35-42. [CrossRef]

25. Macbeth, S.W.; Fernandez, R.L.; Meyers, B.R.; Tan, D.S.; Robertson, G.G.; Oliver, N.M.; Murillo, O.E.; Pedersen, E.R.; Czerwinski, M.P.; Pinckney, M.D.; et al. Activity-Centric Adaptive User Interface. U.S. Patent App. 11/426,804, 27 June 2006.

26. Bartneck, C.; Kulić, D.; Croft, E.; Zoghbi, S. Measurement Instruments for the Anthropomorphism, Animacy, Likeability, Perceived Intelligence, and Perceived Safety of Robots. Int. J. Soc. Robot. 2009, 1, 71-81. [CrossRef]

27. Walters, M.L.; Syrdal, D.S.; Dautenhahn, K.; teBoekhorst, R.; Koay, K.L. Avoiding the uncanny valley: Robot appearance, personality and consistency of behavior in an attention-seeking home scenario for a robot companion. Auton. Robot. 2008, 24, 159-178. [CrossRef]

28. Hassenzahl, M.; Tractinsky, N. User experience-A research agenda. Behav. Inf. Technol. 2006, $25,91-97$. [CrossRef]

29. Liu, J.;Wong, C.K.; Hui, K.K. An adaptive user interface based on personalized learning. IEEE Intell. Syst. $2003,18,52-57$. 
30. Sabanovic, S.; Reeder, S.; Kechavarzi, B. Designing Robots in the Wild: In situ Prototype Evaluation for a Break Management Robot. J. Hum. Robot Interact. 2014, 3, 70. [CrossRef]

31. Lee, H. R.; Šabanović, S.; Chang, W.-L.; Nagata, S.; Piatt, J.; Bennett, C.; Hakken, D. Steps Toward Participatory Design of Social Robots: Mutual Learning with Older Adults with Depression; ACM Press: New York, NY, USA, 2017; pp. 244-253.

32. Weiss, A.; Bernhaupt, R.; Tscheligi, M.; Yoshida, E. Addressing User Experience and Societal Impact in a User Study with a Humanoid Robot. In Proceedings of the Symposium on New Frontiers in Human-Robot Interaction, Edinburgh, Scotland, 8-9 April 2009.

33. De Graaf, M.M.A.; Ben Allouch, S. Exploring influencing variables for the acceptance of social robots. Robot. Auton. Syst. 2013, 61, 1476-1486. [CrossRef]

34. Niemelä, R.; Rautio, S.; Hannula, M.; Reijula, K. Work environment effects on labor productivity: An intervention study in a storage building: Work Environment and Labor Productivity. Am. J. Ind. Med. 2002, 42, 328-335. [CrossRef] [PubMed]

35. Shiomi, M.; Shinozawa, K.; Nakagawa, Y.; Miyashita, T.; Sakamoto, T.; Terakubo, T.; Ishiguro, H.; Hagita, N. Recommendation effects of a social robot for advertisement-use context in a shopping mall. Int. J. Soc. Robot. 2013, 5, 251-262. [CrossRef]

36. Kanda, T.; Shiomi, M.; Miyashita, Z.; Ishiguro, H.; Hagita, N. A communication robot in a shopping mall. IEEE Trans. Robot. 2010, 26, 897-913. [CrossRef]

37. Satake, S.; Kanda, T.; Glas, D.F.; Imai, M.; Ishiguro, H.; Hagita, N. How to Approach Humans?-Strategies for Social Robots to Initiate Interaction. In Proceedings of the 2009 4th ACM/IEEE International Conference on Human-Robot Interaction (HRI), La Jolla, CA, USA, 11-13 March 2009.

38. Kanda, T.; Shiomi, M.; Miyashita, Z.; Ishiguro, H.; Hagita, N. An affective guide robot in a shopping mall. In Proceedings of the 4th ACM/IEEE International Conference on Human-Robot Interaction (HRI), San Diego, CA, USA, 9-13 March 2009; pp. 173-180.

39. Svenstrup, M.; Bak, T.; Maler, O.; Andersen, H.J.; Jensen, O.B. Pilot study of person robot interaction in a public transit space. In Proceedings of the International Conference on Research and Education in Robotics, Heidelberg, Germany, 22-24 May 2008; pp. 96-106.

40. Kato, Y.; Kanda, T.; Ishiguro, H. May I help you?: Design of human-like polite approaching behavior. In Proceedings of the Tenth Annual ACM/IEEE International Conference on Human-Robot Interaction (ACM 2015), Portland, OR, USA, 2-5 March 2015; pp. 35-42.

41. Liu, N.; Woon, W.L.; Aung, Z.; Afshari, A. Handling class imbalance in customer behavior prediction. In Proceedings of the 2014 International Conference on Collaboration Technologies and Systems (CTS), Minneapolis, MN, USA, 19-23 May 2014; pp. 100-103.

42. Gockley, R.; Bruce, A.; Forlizzi, J.; Michalowski, M.; Mundell, A.; Rosenthal, S.; Sellner, B.; Simmons, R.; Snipes, K.; Schultz, A.C.; et al. Designing robots for long-term social interaction. In Proceedings of the 2005 IEEE/RSJ International Conference on Intelligent Robots and Systems, Edmonton, AB, Canada, 2-6 August 2005; pp. 1338-1343.

43. Endsley, M.R. Level of automation effects on performance, situation awareness and workload in a dynamic control task. Ergonomics 1999, 42, 462-492. [CrossRef] [PubMed]

44. Correa, D.S.O.; Sciotti, D.F.; Prado, M.G.; Sales, D.O.; Wolf, D.F.; Osorio, F.S. Mobile Robots Navigation in Indoor Environments Using Kinect Sensor. In Proceedings of the 2012 Second Brazilian Conference on Critical Embedded Systems, Campinas, Brazil, 20-25 May 2012; pp. 36-41.

45. Tsetsos, V.; Anagnostopoulos, C.; Kikiras, P.; Hadjiefthymiades, S. Semantically enriched navigation for indoor environments. Int. J. Web Grid Serv. 2006, 2, 453-478. [CrossRef]

46. Designing Telepresence Robot Systems for Use by People with Special Needs. Available online: http:/ / robotics. cs.uml.edu/fileadmin/content/publications/2011/2011-06-qolt-ktsui-anorton-dbrooks-hyanco-dkontak.pdf (accessed on 8 October 2018).

47. Guizzo, E. When My Avatar Went to Work. IEEE Spectr. 2010, 47, 26-50. [CrossRef]

48. Michaud, F.; Boissy, P.; Labonte, D.; Corriveau, H.; Grant, A.; Lauria, M.; Cloutier, R.; Roux, M.-A.; Iannuzzi, D.; Royer, M.-P. Telepresence robot for home care assistance. In Proceedings of the AAAI Spring Symposium: Multidisciplinary Collaboration for Socially Assistive Robotics, Standford, CA, USA, 26-28 March 2007; pp. 50-55. 
49. Lu, J.-M.; Hsu, Y.-L. Telepresence Robots for Medical and Homecare Applications. In Contemporary Issues in Systems Science and Engineering; Zhou, M., Li, H.-X., Weijnen, M., Eds.; John Wiley and Sons, Inc.: Hoboken, NJ, USA, 2015; pp. 725-735, ISBN 978-1-119-03682-1.

50. Kwon, O.-H.; Koo, S.-Y.; Kim, Y.G.; Kwon, D.-S. Telepresence robot system for English tutoring. In Proceedings of the 2010 IEEE Workshop on Advanced Robotics and its Social Impacts, Seoul, Korea, 26-28 October 2010; pp. 152-155.

51. Giraff Technologies AB. Available online: http://giraff.org (accessed on 8 October 2018).

52. Anybots, It's You Anywhere. Available online: http:/ / www.anybots.com (accessed on 8 October 2018).

53. VGo Communication. Available online: http://www.vgocom.com (accessed on 8 October 2018).

54. Willow Garage. Texai Remote Presence System. Available online: http:/ / www.willowgarage.com/pages/ texai/ overview (accessed on 8 October 2018).

55. Double Robotics, Telepresence Robot for Telecommuters. Available online: https:/ /www.doublerobotics.com/ (accessed on 8 October 2018).

56. Research in Art and Design (Royal College of Art Research Papers, Vol 1, No 1, 1993/4). Available online: http:/ / researchonline.rca.ac.uk/384/ (accessed on 8 October 2018).

57. Lee, M.K.; Kiesler, S.; Forlizzi, J.; Rybski, P. Ripple effects of an embedded social agent: A field study of a social robot in the workplace. In Proceedings of the SIGCHI Conference on Human Factors in Computing Systems (ACM 2012), Austin, TX, USA, 5-10 May 2012; pp. 695-704.

58. Dietsch, J. People Meeting Robots in the Workplace Industrial Activities. IEEE Robot. Autom. Mag. 2010, 17, 15-16. [CrossRef]

59. Elara, M. R.; Rojas, N.; Chua, A. Design principles for robot inclusive spaces: A case study with Roomba. In Proceedings of the 2014 IEEE International Conference on Robotics and Automation (ICRA), Hong Kong, China, 31 May-7 June 2014; pp. 5593-5599.

60. Shiomi, M.; Iio, T.; Kamei, K.; Sharma, C.; Hagita, N. Effectiveness of social behaviors for autonomous wheelchair robot to support elderly people in Japan. PLoS ONE 2015, 10, e0128031. [CrossRef] [PubMed]

61. Lee, M. K.; Forlizzi, J.; Kiesler, S.; Rybski, P.; Antanitis, J.; Savetsila, S. Personalization in HRI: A Longitudinal Field Experiment; ACM Press: New York, NY, USA, 2012; pp. 319-326.

62. Sakamoto, D.; Kanda, T.; Ono, T.; Ishiguro, H.; Hagita, N. Android as a Telecommunication Medium with a Human-Like Presence; ACM Press: New York, NY, USA, 2007; p. 193.

63. Fussell, S.R.; Kiesler, S.; Setlock, L.D.; Yew, V. How People Anthropomorphize Robots; ACM Press: New York, NY, USA, 2008; p. 145.

64. Sumioka, H.; Minato, T.; Matsumoto, Y.; Salvini, P.; Ishiguro, H. Design of human likeness in HRI from uncanny valley to minimal design. In Proceedings of the 2013 8th ACM/IEEE International Conference on Human-Robot Interaction (HRI), Tokyo, Japan, 3-6 March 2013; pp. 433-434.

65. Şahin, E.; Çakmak, M.; Doğar, M.R.; Uğur, E.; Üçoluk, G. To Afford or Not to Afford: A New Formalization of Affordances Toward Affordance-Based Robot Control. Adapt. Behav. 2007, 15, 447-472. [CrossRef]

66. Breazeal, C. Social Interactions in HRI: The Robot View. IEEE Trans. Syst. Man Cybern. Part C 2004, 34, 181-186. [CrossRef]

67. Lohse, M.; van Berkel, N.; van Dijk, E.M.A.G.; Joosse, M.P.; Karreman, D.E.; Evers, V. The influence of approach speed and functional noise on users' perception of a robot. In Proceedings of the 2013 IEEE/RSJ International Conference on Intelligent Robots and Systems, Tokyo, Japan, 3-7 November 2013; pp. 1670-1675.

68. Walters, M.L.; Woods, S.; Koay, K.L.; Dautenhahn, K. Practical and methodological challenges in designing and conducting human-robot interaction studies. In Proceedings of the AISB 05 Symposium on Robot Companions, Hatfield, UK, 14-15 April 2005; pp. 1-143.

69. Dang, T.H.H.; Tapus, A. Stress Game: The Role of Motivational Robotic Assistance in Reducing User's Task Stress. Int. J. Soc. Robot. 2015, 7, 227-240. [CrossRef]

70. Forlizzi, J.; Di Salvo, C. Service robots in the domestic environment: A study of the Roomba Vacuum in the home. In Proceedings of the 1st ACM SIGCHI/SIGART Conference on Human-Robot Interaction, Salt Lake City, UT, USA, 2-4 March 2006.

71. Liu, P.; Glas, D.F.; Kanda, T.; Ishiguro, H.; Hagita, N. A Model for Generating Socially-Appropriate Deictic Behaviors Towards People. Int. J. Soc. Robot. 2017, 9, 33-49. [CrossRef]

72. Ethics of Robotic Aesthetics. Available online: http://www.drhu.eu/publications/2015-DeSForM.pdf\#page= 167 (accessed on 8 October 2018). 
73. Salvini, P.; Laschi, C.; Dario, P. Design for Acceptability: Improving Robots' Coexis-tence in Human Society. Int. J. Soc. Robot. 2010, 2, 451-460. [CrossRef]

74. Sung, J.; Grinter, R.E.; Christensen, H.I. "Pimp My Roomba": Designing for Personalization; ACM Press: New York, NY, USA, 2009; p. 193.

75. Walsh, D.; Lin, L.C.; Dils, P.B. Context-Adaptive User Interface for a Portion of a Display Screen. U.S. Patent D678,898, 26 March 2013.

76. Beer, J.; Fisk, A.D.; Rogers, W.A. Toward a framework for levels of robot autonomy in human-robot interaction. J. Hum. Robot Interact. 2014, 3, 74. [CrossRef] [PubMed]

77. Heerink, M.; Krose, B.; Evers, V.; Wielinga, B. The influence of social presence on enjoyment and intention to use of a robot and screen agent by elderly users. In Proceedings of the 17th IEEE International Symposium on Robot and Human Interactive Communication, Technische Universität München, Munich, Germany, 1-3 August 2008; pp. 695-700.

78. Google. Material Design principles. Available online: https://material.io/design/introduction/principles (accessed on 8 October 2018).

79. Gwinner, K.P.; Gremler, D.D.; Bitner, M.J. Relational Benefits in Services Industries: The Customer's Perspective. J. Acad. Market. Sci. 1998, 26, 101-114. [CrossRef]

80. Mandryk, R.L.; Atkins, M.S.; Inkpen, K.M. A continuous and objective evaluation of emotional experience with interactive play environments. In Proceedings of the SIGCHI Conference on Human Factors in Computing Systems, Montreal, QC, Canada, 22-27 April 2006; pp. 1027-1036.

81. Rousseau, V.; Ferland, F.; Létourneau, D.; Michaud, F. Sorry to interrupt, but may I have your attention? Preliminary design and evaluation of autonomous engagement in HRI. J. Hum. Robot Interact. 2013, 2, 41-61. [CrossRef]

82. Lehmann, H.; Saez-Pons, J.; Syrdal, D.S.; Dautenhahn, K. In Good Company? Perception of Movement Synchrony of a Non-Anthropomorphic Robot. PLoS ONE 2015, 10, e0127747. [CrossRef] [PubMed]

83. Lupetti, M.; Yao, Y.; Mi, H.; Germak, C. Design for Children's Playful Learning with Robots. Future Internet 2017, 9, 52. [CrossRef]

84. Kiesler, S.; Hinds, P. Introduction to this special issue on human-robot interaction. Hum. Comput. Interact. 2004, 19, 1-8. [CrossRef]

85. Scholtz, J. Theory and evaluation of human robot interactions. In Proceedings of the 36th Annual Hawaii International Conference on System Sciences, Big Island, HI, USA, 6-9 January 2003; p. 10.

86. Khan, Z. Attitudes towardss Intelligent Service Robots; NADA KTH: Stockholm, Sweden, 1998; p. 17.

87. Everett M Rogers. Rogers, E.M. Diffusion of Innovation, 5th ed.; The Free Press: New York, NY, USA, 1995.

88. Montgomery, C. Woody's roundup and Wall- E's wunderkammer. Technophilia and nostalgia in Pixar animation. Anim. Stud. 2011, 6, 7-13.

89. Forsythe, S.; Kim, J.O.; Petee, T. Product cue usage in two Asian markets: A cross cultural comparison. Asia Pac. J. Manag. 1999, 16, 275-283. [CrossRef]

90. Schermerhorn, P.; Scheutz, M.; Crowell, C.R. Robot social presence and gender: Do females view robots differently than males? In Proceedings of the 3rd ACM/IEEE International Conference on Human Robot Interaction, Amsterdam, The Netherlands, 12-15 March 2008; pp. 263-270.

91. Kuo, I.H.; Rabindran, J.M.; Broadbent, E.; Lee, Y.I.; Kerse, N.; Stafford, R.M.Q. Age and gender factors in user acceptance of healthcare robots. In Proceedings of the 18th IEEE International Symposium on Robot and Human Interactive Communication, Toyama, Japan, 27 Septembet-2 October 2009; pp. 214-219.

92. Fong, T.; Nourbakhsh, I.; Dautenhahn, K. A survey of socially interactive robots. Robot. Auton. Syst. 2003, 42, 143-166. [CrossRef]

93. Asif, M.; Sabeel, M.; Mujeeb-ur Rahman, K.Z.Waiter robot-solution to restaurant automation. In Proceedings of the 1st student multi disciplinary research conference (MDSRC), At Wah, Pakistan, 14-15 November 2015. 
94. Baraka, K.; Veloso, M.M. Mobile Service Robot State Revealing Through Expressive Lights: Formalism, Design, and Evaluation. Int. J. Soc. Robot. 2018, 10, 65-92. [CrossRef]

95. Aly, A.; Tapus, A. A model for synthesizing a combined verbal and nonverbal behavior based on personality traits in human-robot interaction. In Proceedings of the 8th ACM/IEEE International Conference on Human-Robot Interaction, Tokyo, Japan, 3-6 March 2013; IEEE Press: Piscataway, NJ, USA, 2013; pp. 325-332. 